\title{
Uterine Corpus Cancer pMO TNM Finding
}

National Cancer Institute

\section{Source}

National Cancer Institute. Uterine Corpus Cancer pMO TNM Finding. NCI Thesaurus.

Code C61357.

Uterine corpus cancer in which there is no evidence of distant metastasis. (from AJCC 6th Ed.) 